\title{
Review
}

\section{The oral contraceptive pill: a revolution for sportswomen?}

\author{
Kim Bennell, Susan White, Kay Crossley
}

\begin{abstract}
Objectives-To determine the effects of the oral contraceptive pill (OCP) on skeletal health, soft tissue injury, and performance in female athletes.

Methods-A literature review was performed using literature retrieval methods to locate relevant studies.

Results-Most female athletes primarily choose to use the OCP for contraceptive purposes, but cycle manipulation and control of premenstrual symptoms are secondary advantages of its use. The effect of the OCP on bone density in normally menstruating women is unclear, with some studies reporting no effect, others a positive effect, and some even a negative effect. The OCP is often prescribed for the treatment of menstrual disturbances in female athletes, and improvements in bone density may result. Whether the OCP influences the risk of stress fracture and soft tissue injuries is not clear from research to date. Effects of the OCP on performance are particularly relevant for elite sportswomen. Although a reduction in $\mathrm{Vo}_{2} \mathrm{MAX}$ has been reported in some studies, this may not necessarily translate to impaired performance in the field. Moreover, some studies claim that the OCP may well enhance performance by reducing premenstrual symptoms and menstrual blood loss. A fear of weight gain with the use of the OCP is not well founded, as population studies report no effect on weight, particularly with the lower dose pills currently available.

Conclusions-Overall, the advantages of the pill for sportswomen would appear to outweigh any potential disadvantages. Nevertheless, there is individual variation in response to the OCP and these should be taken into account and monitored in the clinical situation. Women should be counselled as to the range of potential benefits and disadvantages in order to make an informed decision based on individual circumstances.
\end{abstract}

(Br F Sports Med 1999;33:231-238)

Keywords: oral contraceptive pill; contraceptive pill; menstrual; exercise; performance; injury
Research from the early 1980s indicated that the contraceptive practices of athletic women differed from those of their sedentary counterparts. ${ }^{1}$ In particular, the use of the oral contraceptive pill (OCP) was low compared with the general population. More recent studies, ${ }^{2}{ }^{3}$ however, have shown that the OCP is used at least as often by athletic women. The reasons given for use of the OCP in these studies are predominantly contraceptive, but also include bone health, cycle manipulation, and control of premenstrual symptoms. This increased rate of OCP use among sportswomen may be attributed to the availability of lower dose pills (30 $\mu$ g oestrogen, and more recently $20 \mu \mathrm{g}$ ), as well as dose reduction and changes to the progestogen component (gestodene). If athletic women are choosing to use the OCP in increasing numbers, it is imperative that the physiological effects, both positive and negative, and their impact on performance and health are considered and discussed with these athletes so an informed decision can be made about the use of this medication. This review focuses on the effects of the OCP on skeletal health, risk of soft tissue injuries, and performance, as these are areas of concern for female athletes and their coaches.

\section{What is the OCP?}

The OCP is usually prescribed in the form of a combined oestrogen and progesterone tablet. The combined pill can be presented as a monophasic pill in which the dose of both hormones is constant throughout the cycle. This form allows easy manipulation of cycles for competition and travel. There is also a triphasic form in which the doses of the hormones vary three times. This form is thought to mimic the "natural" cycle more closely than other types and usually has a slightly lower overall dose of hormones. Its main drawback is difficulty with cycle manipulation because of the varying doses throughout the packet. A biphasic preparation is also available but this is not as popular as the other forms, as it offers no particular advantage than the other two preparations. In some circumstances, such as breast feeding or sensitivity to the oestrogen component, a progesterone only pill (the "mini-pill") may be used.

When the OCP was first introduced in the $1960 \mathrm{~s}$, the oestrogen dose was as high as $150 \mu \mathrm{g}$ 
ethinyloestradiol, with the progestogen component reaching $250 \mu \mathrm{g}$ levonorgestrel. By the mid 1970 s, the most commonly prescribed pills contained $50 \mu \mathrm{g}$ ethinyloestradiol. The currently available OCPs now contain $35 \mu \mathrm{g}$ (or less) oestrogen usually as ethinyloestradiol. A $20 \mu \mathrm{g}$ (with $100 \mu \mathrm{g}$ levonorgestrel) pill is also now on the market. The progestogen type and dose are more variable but the newer forms (gestodene, desogestrol) are claimed to have fewer side effects than the older ones. There is little information about the physiologically bioavailable oestradiol and progesterone concentrations in women taking oral contraceptives.

\section{What are the potential advantages of OCP use in the female athlete?}

The most obvious benefit of the OCP is its action as a reliable and reversible form of contraception $(96 \%$ successful when used correctly). ${ }^{4}$ Other benefits include decreasing the risk of iron deficiency anaemia by decreasing menstrual blood loss and allowing manipulation of the menstrual cycle for travel, training, and competition commitments. Benefits not specifically related to athletic females include a decreased risk of ectopic pregnancy, benign breast disease, and ovarian and endometrial cancer. ${ }^{5}{ }^{6}$ Other possible benefits that will be discussed in more detail include a positive effect on premenstrual symptoms with a possible resultant effect on performance and injury risk at this time. Its role in the treatment of amenorrhoeic osteoporosis and stress fracture risk will also be discussed.

\section{What are the potential disadvantages of OCP use in the female athlete?}

As with every medication there are potential side effects of the OCP. These include "nuisance" ones such as headaches, breast tenderness, fluid retention, nausea, and possibly weight gain. All of these effects may have some negative impact on an athlete's performance and injury risk either in a physical or psychological form. Other negatives not specific to athletes include the possibility of a small risk of developing hypertension, thromboembolism, and cerebrovascular disease, ${ }^{78}$ with some reports of a small increase in the risk of breast cancer in long term users. ${ }^{9}$ However, most of the vascular complications relate to the higher dose pills and are more common in smokers with other cardiovascular risk factors. ${ }^{10}$ There are specific contraindications to the use of the OCP which should be determined before prescribing this drug.

The issue of weight gain is of great concern to both athletes and, often more so, their coaches, particularly in low body weight sports such as distance running, light weight rowing, and gymnastics. Most population studies indicate no overall effect on body weight while taking the OCP, ${ }^{11}{ }^{12}$ although individual responses to the hormones may involve some weight gain as the result of either fluid retention or possibly appetite stimulation. The newer $20 \mu \mathrm{g}$ OCP claims to have the least effect on weight gain of all the currently available pills. Athletes should be counselled about the misconception of weight gain as an inevitable consequence of OCP use.

The potential for the OCP to impact negatively on aerobic, anaerobic, and strength parameters of performance will be discussed later in this article.

\section{Methodology issues}

There have been a number of studies relating to the use of OCP by female athletes, but many have methodology flaws which limit the value of the findings. The main problem is the lack of clinical trials using key methodological features to minimise bias including randomisation, specification of eligibility criteria, blind outcome assessment, and adequate sample size. Many of the studies are case series, which are useful for generating hypotheses but cannot be used to assign causality. Others tend to be cross sectional designs comparing past or present users and non-users of the OCP. These have problems relating to accurate recall of pill usage $^{13}$ and to improper matching of groups to control for potential confounding variables. The conflicting results found in the literature are also hard to interpret given differences between studies including pill dosage and formulation, menstrual history, duration of OCP use, age at which subjects were exposed to OCP, and outcome measurements. Because of these problems, it is difficult at this stage to state conclusively the effect of the OCP on skeletal health, injury risk, and performance in female athletes.

\section{Effects of the OCP on skeletal health}

IS THERE A RELATION BETWEEN USE OF THE OCP AND BONE DENSITY?

As both of the component hormones of the combined OCP have been shown to influence bone metabolism, it is reasonable to hypothesise that use of the OCP could influence skeletal health in athletes. Most studies of the relation between OCP use and bone density involve cross sectional or longitudinal designs in healthy non-athletic cohorts. Confounding variables that were often not well controlled include smoking, alcohol intake, past menstrual status, body composition, dietary intake, and physical activity levels.

Some studies in healthy women have shown greater bone mass in current or past users of the OCP than in non-users. ${ }^{14-16}$ Conversely, a number of others have failed to find an association between the OCP and bone mass in either normally active women ${ }^{17-21}$ or sportswomen..$^{22-25}$

More unexpectedly, there have been several recent reports of detrimental effects of the OCP on bone mass ${ }^{26-29}$ and fracture risk. ${ }^{30} \mathrm{~A}$ well designed randomised study of 207 skeletally immature primates found that the OCP group (low dose, Triphasil) gained less bone mineral than controls over 20 months.$^{28}$ Similar results were noted in a five year longitudinal study of 147 young women aged 19-22 years taking a monophasic OCP. ${ }^{26} \mathrm{~A}$ cross sectional study of 128 women aged 20-35 years found 
no beneficial effect of exercise on bone density in women with prolonged use of the OCP, ${ }^{27}$ raising the issue of whether active women taking the OCP at an earlier age will develop an adequate peak bone density. A recent abstract describing a population based national sample of young adult women also reported negative bone density effects with the first use of the OCP at a young gynaecological age and with prolonged OCP use. ${ }^{29}$ In the largest study to date (46000 women with a mean age at recruitment of 29 years), women who used oral contraceptives were at significantly higher risk for subsequent fractures than those who had never used them. ${ }^{30}$

The clinical implications of these negative findings need to be kept in perspective until further scientifically rigorous studies are conducted. These will help to establish whether reported detrimental effects are due to actual prevention of bone accretion and suppression of bone turnover or to methodological issues such as lifestyle factors ${ }^{29}$ and history of menstrual disturbances in OCP users which are themselves associated with low bone density.

Despite the fact that the OCP is commonly prescribed as a treatment for menstrual disturbances, its ability to improve bone mass in amenorrhoeic athletes has not been well investigated. Similar to the postmenopausal state, amenorrhoea and oligomenorrhoea are associated with low oestrogen and progesterone levels, with loss of bone particularly at the trabecular lumbar spine. ${ }^{31-35}$ There is also evidence that subclinical menstrual disturbances such as shortened luteal phase may lead to reductions in bone density. ${ }^{36}{ }^{37}$ However, unlike post-menopausal women, in whom bone turnover, and hence bone resorption, is increased, athletes with menstrual disturbances appear to have normal ${ }^{38}$ or possibly lower ${ }^{39} 40$ bone turnover. Oestrogen therapies are successful in retarding bone loss in postmenopausal women when they act mainly by inhibiting bone resorption. This effect may not necessarily be seen in amenorrhoeic athletes.

Nevertheless, there is some support for a possible skeletal benefit from the OCP in athletes with menstrual disturbances. A cross sectional study found that sportswomen who had been amenorrhoeic for less than three years and who had taken the OCP or had oestrogen treatment at some stage after had similar spinal bone density to those with regular menses since menarche. ${ }^{41}$ In a randomised study of 15 females aged 14 to 28 years with hypothalamic amenorrhoea, treatment with the OCP (0.035 mg ethinyloestradiol) for 12 months was associated with improvements in bone mineral at the lumbar spine and total body but not at the hip compared with medroxyprogesterone or placebo treatment. ${ }^{42}$ Improved bone mineral with the OCP was independent of weight gain. However, the sample size was small and heterogeneous, including patients with eating disorders as well as athletes with exercise induced menstrual disturbances.
A limited number of prospective studies have trialled other hormone replacement therapies in active women with menstrual disturbances. In a non-randomised study, De Cree et $a t^{43}$ found a significant increase of $9.5 \%$ at the lumbar spine in seven amenorrhoeic athletes after eight months of treatment with ethinyloestradiol combined with cyproterone acetate, an antiandrogenic agent that also has progestagenic effects. This contrasted with a $1.6 \%$ increase in four untreated controls. A clinical study showed that vertebral and femoral neck bone density increased significantly in eight female runners with exercise associated amenorrhoea who took hormone replacement therapy compared with five who refused medication but who were followed up as controls over 24 to 30 months. ${ }^{44}$

A possible role for progesterone therapy alone was found in a randomised double blind placebo controlled study. ${ }^{45}$ Cyclic medroxyprogresterone for one year resulted in a $1.7 \%$ increase in spinal bone density in 21-45 year old physically active women with a range of menstrual disturbances. The greatest effect was found in those with the lowest initial bone density. This, however, contrasts with the findings of Hergenroeder et $a l^{42}$ showing that 12 months of medroxyprogesterone treatment did not influence lumbar spine or hip bone density in oligomenorrhoeic women.

Based on the conflicting research to date and the lack of well controlled studies, it is difficult to state conclusively the skeletal effects of the OCP in normally menstruating sportswomen. In those with menstrual disturbances, the OCP and other hormone replacement regimens may be effective in improving bone density and therefore should be considered as treatment options in the management of these athletes. Questions remain including: (a) what is the best hormone formulation and dose for skeletal gains? (b) is hormone replacement more or less effective than spontaneous resumption of menses? (c) does treatment with the OCP or other hormones lead to complete restoration of bone in these women? Answers to such questions will assist in the development of evidence based guidelines for clinical practice.

DOES USE OF THE OCP REDUCE THE RISK OF STRESS FRACTURES?

Stress fractures arise from accumulation of bone microdamage which cannot be adequately repaired by the remodelling process. Theoretically, low bone density could contribute to the development of a stress fracture by decreasing the fatigue resistance of bone to loading. ${ }^{47}$ Menstrual disturbances may have an effect on stress fracture aetiology through the influence of reduced levels of oestrogen and progesterone on both bone remodelling and bone density. ${ }^{48-50}$ A limited number of cross sectional studies have compared regional bone density in small groups of female athletes with and without stress fracture but results have been conflicting. ${ }^{51-56}$ The findings of the only prospective study to date indicate that lower bone density is a risk factor for stress fractures in female track and field athletes. ${ }^{57}$ 
In general, stress fractures are more common in athletes with menstrual disturbances, in whom the relative risk may be up to four times greater than that of eumenorrhoeic athletes. ${ }^{51-55}$ 57-62 The risk of multiple stress fractures also seems to be increased in sportswomen with irregular or absent menses. ${ }^{6063}$

The OCP could theoretically influence stress fracture rates by affecting bone remodelling and bone density. As bone is continually being remodelled and in this process there is a lag between bone resorption and formation, at some sites it may be in a weakened state and vulnerable to accumulation of microdamage. It is feasible that, by reducing bone turnover rates, the OCP may be able to reduce the risk of stress fracture development. Furthermore, if the OCP has positive effects on bone density, this may increase bone strength and enhance its ability to resist fracture.

Two prospective cohort studies, one in athletes $^{57}$ and one in female marines, ${ }^{62}$ have failed to support a protective effect of OCP use on stress fracture development, although numbers in the stress fracture groups were relatively small. The results of cross sectional studies are contradictory. Barrow and Saha ${ }^{60}$ found that runners using the OCP for at least one year had significantly fewer stress fractures $(12 \%)$ than non-users $(29 \%)$. This was supported by the findings of Myburgh et al. ${ }^{53}$ Conversely, no difference in OCP use was reported in ballet dancers with and without stress fractures. ${ }^{61}$ However, few dancers were taking the OCP. As these studies are retrospective in nature, it is not known whether the athletes were taking the OCP before or after the stress fracture episode.

It is possible that the influence of the OCP on stress fracture risk will differ depending on prior menstrual status. The risk of stress fracture may only be reduced in sportswomen with menstrual disturbances who subsequently take the OCP. In those with regular ovulatory cycles, exogenous oestrogen acquired through OCP use may confer no further benefit with regard to stress fracture. This issue has not been investigated, and, given the conflicting results to date, the OCP should not be prescribed solely for the purpose of preventing stress fractures in normally menstruating women.

Effects of the OCP on soft tissue injuries Indirect support for a theoretical link between the OCP and soft tissue injuries comes from studies of the risk of injury across the menstrual cycle and studies relating menstrual disturbances to injury incidence. Any association must be viewed with caution as injury risk is multifactorial. Unless these factors are taken into account or controlled for, it is difficult to establish the relative importance of each factor.

A limited number of retrospective and prospective studies have suggested that the risk of musculoskeletal injury may be greater during the premenstrual and menstrual phases. ${ }^{64-66}$ Limitations of these studies include a reliance on recall for injury occurrence and menstrual cycle phase and a lack of hormonal analysis to confirm menstrual phase.

There is some support for a correlation between menstrual irregularities and injuries. Lloyd $e t a l^{8}$ found that women participants of a $10 \mathrm{~km}$ road race who had suffered injury related interruptions to their running were significantly more likely to have had irregular or absent menses than all other runners. Similarly, a retrospective cohort study of track and field athletes showed that women who sustained multiple injuries over the 12 month period had a significantly later age of menarche and were more likely to have had a history of menstrual disturbances than the injury-free group. ${ }^{67}$

There are conflicting results from the few studies that have investigated the relation between use of the OCP and soft tissue injuries. Support for a beneficial effect of the OCP on injury incidence comes from a 12 month prospective study by Moller-Nielson and Hammer, ${ }^{66}$ in which female soccer players using the OCP had fewer traumatic injuries than a well matched group of non-pill users. Similarly, runners with an interrupted running history because of injury were less likely to have used the OCP during their training programmes. ${ }^{58}$ In this retrospective study, runners who did not use the OCP, had irregular menses, or had been running for a longer period had a higher risk of injury. A cross sectional study reported that OCP use attenuated delayed onset muscle soreness after a bout of exercise. ${ }^{68}$ This suggests that oestrogen may serve to protect skeletal muscle from exercise induced damage.

In contrast with these findings, Bennell and Crossley ${ }^{67}$ reported no significant difference between injured and uninjured track and field athletes with respect to OCP use. Brynhildsen et $a l^{69}$ also found no difference in the prevalence or severity of low back pain between OCP and non-OCP users in a small group of female soccer players. However, back pain may represent a different entity from acute soft tissue injuries and may not be influenced to the same extent by the OCP.

If indeed there is an association between use of the OCP and decreased injury risk, what are the possible explanations? It has been suggested that a reduction in premenstrual symptoms (such as dysmenorrhoea, fatigue, fluid retention, and weight gain) caused by the $\mathrm{OCP}^{50}$ could positively influence performance. A large retrospective survey showed that $59 \%$ of regularly exercising women noted impaired performance during the premenstrual phase in conjunction with increasing premenstrual symptoms. ${ }^{71}$ Posthuma et $a l^{2}$ reported a decrease in manual dexterity during the premenstrual phase among women with premenstrual symptoms, while the opposite was found among asymptomatic women.

Risk of injury may be related to premenstrual symptoms. In the study by Moller-Nielson and Hammer, ${ }^{66}$ the significantly higher risk of injury in the premenstrual and menstrual phase of the menstrual cycle was most evident in those players with abdominal congestion or swelling, or in those who cited more than one 
premenstrual symptom. Women who did not exhibit any premenstrual symptoms showed no predisposition to injury during these phases. This finding of increased injury risk in the premenstrual and menstrual phase was not evident in those taking the OCP, which may be related to a reduction in premenstrual symptoms. ${ }^{70}$

A possible association between the OCP and injury risk could also be due to the direct effect of female sex hormones on the growth and development of soft tissue structures. ${ }^{73}{ }^{74}$ For example, oestrogen receptors have been identified in the fibroblasts of the human anterior cruciate ligament. ${ }^{7576} \mathrm{Liu}$ et $a l^{75}$ found that fluctuations in serum oestrogen levels led to alterations in anterior cruciate ligament fibroblast metabolism, which may result in structural and compositional changes in the ligament. To date, no studies have evaluated the effect of the OCP on joint and muscle structure in either an animal model or a human clinical trial.

A link between the OCP and soft tissue injuries is still tenuous because of a paucity of well controlled studies. At this stage, athletes cannot be advised that the OCP will definitely reduce the incidence of musculoskeletal injuries.

\section{The OCP and performance}

DOES THE OCP AFFECT AEROBIC AND ANAEROBIC PERFORMANCE?

There is disagreement about the direction and magnitude of OCP effects on various physiological tests and the extent to which these translate into effects on performance in the field setting. As with other OCP studies, the discrepancy may be related to methodology differences including the study design, the use of trained versus untrained subjects, the pill dosage, the duration of pill use, and the choice of outcome measures.

Some investigators have reported reductions in $\mathrm{VO}_{2} \mathrm{MAX}$ associated with use of the OCP which appear to be reversible after cessation of its use. In a case series of seven active women taking the OCP for two months, Dagget et al ${ }^{77}$ reported a significant $11 \%$ decrease in $\mathrm{VO}_{2} \mathrm{MAX}$ from a mean of 44.6 to $39.8 \mathrm{ml} / \mathrm{kg} / \mathrm{min}$. This effect was reversed six weeks after they stopped taking the pill. A double blind randomised trial studied the effect of a low dose triphasic OCP (ethinyloestradiol and norethindrone) on performance variables in 14 elite athletes ${ }^{78}$ In both groups there was a slight decrease in $\mathrm{VO}_{2} \mathrm{MAX}$ from the follicular to the luteal phase. After two months on the OCP, the treatment group had a further $5 \%$ decrease in $\mathrm{VO}_{2} \mathrm{MAX}$ while the placebo group had a slight increase $(1.5 \%)$. There was no change in other variables measured including maximum heart rate and anaerobic and aerobic endurance at $90 \%$ $\mathrm{VO}_{2}$ MAX. One of the few published prospective trials involving trained subjects studied the effects of the OCP over a six month period in six women randomised to a low dose OCP (35 $\mu \mathrm{g}$ ethinyloestradiol, $0.4 \mathrm{mg}$ norethindrone) group and six controls. ${ }^{79}$ In the OCP group there was a $7 \%$ decline in $\mathrm{VO}_{2} \mathrm{MAX}(41.2 \mathrm{ml} / \mathrm{kg} /$ $\min$ to $38.4 \mathrm{ml} / \mathrm{kg} / \mathrm{min}$ ), with the control group showing a slight improvement over the same period. All changes had returned to normal when retested at one month after cessation of the medication. It would have been interesting to employ a cross over design to further strengthen the finding of a negative effect of the OCP.

Conversely, others have failed to confirm a negative effect of the OCP on performance in laboratory tests. In a prospective randomised study of 10 women and 15 men, a low dose OCP ( $1 \mathrm{mg}$ norethindrone and $35 \mu \mathrm{g}$ ethinyloestradiol) taken over a single cycle did not have any effect on $\mathrm{VO}_{2} \mathrm{MAX}$ during treadmill running, an endurance running test, or breathing rate. ${ }^{79 a}$ Evaluation of the effects after longer duration of OCP use would have been useful. These findings have been supported by cross sectional aerobic and anaerobic comparisons of women taking and not taking the OCP. ${ }^{80} 81 \mathrm{In}$ particular, a recent study by Lynch and Nimmo ${ }^{81}$ found no differences in exercise performance between groups despite differences in metabolism including temperature and blood lactate.

From the available evidence it seems that there may be a slight reduction in $\mathrm{VO}_{2} \mathrm{MAX}$ with the OCP in some individuals but this is reversible when the medication is stopped. Whether this translates to a detrimental effect on exercise performance, particularly at the elite level, is not clear, especially as performance is influenced by a myriad of other factors, all of which could overwhelm any OCP influence. For example, a reduction in premenstrual symptoms by the OCP could well improve performance at this time. It is also possible that adaptations to the OCP may occur, and research comparing the responses over time would establish whether effects are maintained with continued use. The effects of the lowest dose $(20 \mu \mathrm{g})$ pills are not known, but if there is a linear relation with dose, any detrimental effects would be expected to be lessened with these pills.

HOW DOES THE OCP INFLUENCE THE CARDIOVASCULAR AND PULMONARY SYSTEMS? Menstrual blood loss together with inadequate dietary iron intake place female athletes at risk of iron deficiency anaemia. ${ }^{82} 83$ The OCP has been found to reduce menstrual blood loss by up to one half. ${ }^{5}$ This could positively impact on performance, particularly in athletes with menorrhagia.

In an early study, ${ }^{84}$ cardiac output was significantly greater in women on a combined high dose OCP, followed by women in the progestin only group, with the controls having the lowest output. The OCP has also been shown to be associated with higher blood volume, stroke volume, and cardiac output during exercise ${ }^{85}$ potentially increasing oxygen delivery to tissues. These cardiac output changes may be secondary to an increase in vascular volume mediated through a hormonally induced increase in aldosterone secretion. 
HOW IS MUSCLE STRENGTH AFFECTED BY THE OCP?

Oestrogen may have a muscle strengthening action. This could explain the findings of a decline in muscle strength around the menopause in women, which is reversed with hormone replacement therapy. ${ }^{86}$ Few studies have investigated the effect of the OCP on muscle strength in female athletes. Cross sectional comparisons of pill and non-pill users have generally found no differences in strength of various muscles. ${ }^{87-89}$ This is supported by the findings of a prospective trial, ${ }^{78}$ which failed to find any significant differences in strength of knee flexion/extension between the placebo and low dose OCP groups after two months. The only exception is a cross sectional study by Wirth and Lohman, ${ }^{90}$ which tested 10 controls and 16 OCP users (on eight different types of oral contraceptive pills) for handgrip endurance time and force output. Both muscle indices were lower in the OCP taking group.

Fluctuations in muscle strength have been noted across the normal menstrual cycle and these appear to be related to changes in oestradiol levels. More specifically, increases in muscle strength have been reported late in the follicular phase corresponding to increases in oestradiol before ovulation. ${ }^{88} 89$ Strength is reduced in the luteal phase which may be due to a detrimental effect of increases in deep muscle temperature..$^{8788}$ Use of the OCP is associated with elimination of these fluctuations in muscle strength. ${ }^{87-90}$ While well designed randomised control trials are lacking, overall it would appear that the OCP does not affect muscle strength but does reduce strength variations associated with the normal menstrual cycle. It is unlikely that this would impact negatively on performance.

ARE THERE CHANGES IN METABOLIC RESPONSES AND SUBSTRATE UTILISATION WITH EXERCISE DURING OCP USE?

Detrimental effects on blood lipids (in relation to cardiovascular disease risk factors) have been described with the higher dose $(50 \mu \mathrm{g})$ OCPs, but the low dose varieties do not seem to have such significant effects. Notelovitz et $a l^{79}$ and Gray et $a l^{91}$ showed no difference in serum cholesterol, triglycerides, and high density lipoproteins between active controls and those on low dose OCPs. This has led to the hypothesis that exercise itself may compensate for the potentially negative effects of some OCPs.

OCP use, in particular at the higher dose, has been associated with decreased glucose tolerance, as evidenced by decreased insulin sensitivity, increased basal glucose levels, and increased plasma insulin levels in response to an oral glucose load. ${ }^{92}$ However, insulin binding does not seem to be changed with low dose triphasic OCPs. ${ }^{93}$

Substrate utilisation during exercise has been studied by a number of researchers. A study by Bemben et a $l^{94}$ found lower blood glucose levels and lower total amount of carbohydrate used during prolonged submaximal exercise in eight low dose OCP users compared with eight controls. This study showed no change in free fatty acid levels with exercise, but Bonen et $a l^{95}$ documented an increase in free fatty acids with exercise in association with the lower blood glucose levels.

An increase in growth hormone response to exercise with the OCP has also been shown ${ }^{94} 95$ and may be due to direct stimulation by the oestrogen component of the pill or possibly as a response to the lower blood glucose levels seen in this group during exercise.

These results suggest that OCP users may have a greater carbohydrate sparing ability during prolonged exercise, thus delaying time to fatigue. An alternative explanation is that the possible change in substrate utilisation from glucose to free fatty acids is a compensatory response to decreased hepatic glucose release, and, even with an increase in free fatty acid availability, endurance performance may be negatively affected. The impact of these changes to substrate metabolism on performance is not understood and further research is required to gain a better understanding of the effect these changes may have in the field. Readers are referred to an excellent review by $\mathrm{LeBrun}^{78}$ for more detail on this complex area.

\section{Conclusion}

Overall the contraceptive and noncontraceptive benefits of the OCP appear to outweigh the potential disadvantages, especially with the low dose pills currently available. Reductions in premenstrual symptoms, less menstrual blood loss, the ability to manipulate the timing of the cycle, lowered risk of musculoskeletal injury, and increases in bone density in those with menstrual disturbances are potential OCP benefits for the sportswoman. However, individual responses to the OCP are variable and these must be taken into consideration in any clinical situation.

1 Jarrett JC, Spellacy WN. Contraceptive practices of female runners. Fertil Steril 1983;39:374-5.

2 White S, Brukner PD. Contraceptive practices and knowledge of elite Australian female athletes. Australian Sports Medicine Federation Annual Scientific Meeting, Perth, 1992

3 Shawdon E. Women's health issues in the elite female athlete. Australian Conference of Science and Medicine in Sport, Hobart, 1995

4 Potter LS. How effective are contraceptives: the determination and measurement of pregnancy rates. Obstet Gynecol 1996;88:S13-23.

5 Mishell DR. Noncontraceptive benefits of oral contraceptives. F Reprod Med 1993;38:1021-9.

6 Tzingounis V, Cardamakis E, Ginopoulos P, et al. Incidence of benign and malignant breast disorders in women taking hormone (contraceptive pill or hormonal replacement therapy). Anticancer Res 1996;16:3997-4000.

7 Brady WA, Kritzsilverstein D, Barrettconnor E, et al. Prior oral contraceptive use is associated with higher blood pressure in older women. Fournal of Women's Health 1998;7: 221-8.

8 Johnston SC, Colford JM, Gress DR. Oral contraceptives and the risk of subarachnoid hemorrhage: a meta-analysis. Neurology 1998;51:411-18.

9 Ursin G, Ross RK, Sullivanhalley J, et al. Use of oral contraceptives and risk of breast cancer in young women. Breast Cancer Res Treat 1998;50:175-84.

10 Schwingl PJ, Ory HW, Visness CM. Estimates of the risk of cardiovascular death attributable to low-dose oral contraceptive in the United States. Am F Obstet Gynecol 1999;180: 241-9.

11 Dusterberg B, Ellman H, Muller H, et al. A three year clinical investigation into efficacy, cycle control and tolerability of a new low-dose monophasic oral contraceptive containing gestodene. Gynecol Endocrinol 1996;10:33-9.

12 Rosenberg $M$. Weight change with oral contraceptive use and during the menstrual cycle: results of daily measurements. Contraception 1998;58:345-9. 
13 Harlow SD, Linet MS. Agreement between questionnaire data and medical records. The evidence for accuracy of recall. Am 7 Epidemiol 1989;129:233-48.

14 Sowers MF, Wallace RB, Lemke JH. Correlates of forearm bo bone mass among women during maxir.
zation. Prevent Med 1985;14:585-96.

15 Lindsay JR, Tohme J, Kanders B. The effect of oral contraceptive use on vertebral bone mass in pre- and postmenopausal women. Contraception 1986;34:333-40.

16 Recker RR, Davies M, Hinders SM, et al. Bone gain in young adult women. $\mathcal{F A M A}$ 1992;268:2403-8.

17 Hreshchyshyn MM, Hopkins A, Zylstra S, et al. Associations of parity, breast-feeding, and birth control pills with lumbar spine and femoral neck bone densities. Am F Obstet Gynecol 1988;159:318-22.

18 Mazess RB, Barden HS. Bone density in premenopausal women: effects of age, dietary intake, physical activity, womoking, and birth-control pills. Am f Clin Nutr1991;53: smoking,

19 Rodin A, Chapman M, Fogelman I. Bone density in users of combined oral contraception. Preliminary reports of a pilot study. British fournal of Family Planning 1991;16:125-9.

20 Hansen MA. Assessment of age and risk factors on bone density and bone turnover in healthy premenopausal women. Osteoporos Int 1994;4:123-8.

21 Garnero P, Sornayrendu E, Delmas PD. Decreased bone turnover in oral contraceptive users. Bone 1995;16:499503.

22 Davee AM, Rosen CJ, Adler RA. Exercise patterns and trabecular bone density in college women. F Bone Miner Res 1990;5:245-50

23 Wolman RL, Clark P, McNally E, et al. Dietary calcium as a statistical determinant of spinal trabecular bone density in amenorrhoeic and oestrogen-replete athletes. Bone Miner 1992;12:415-23.

24 Taaffe DR, Snow-Harter C, Connolly DA, et al. Differential effects of swimming versus weight-bearing activity on bone mineral status of eumenorrheic athletes. F Bone Miner Res mineral status of

25 Keay N, Fogelman I, Blake G. Bone mineral density in professional female dancers. Br F Sports Med 1997;31:143-

26 Polatti F, Perotti F, Filippa N, et al. Bone mass and long-term monophasic oral contraceptive treatment in young women. Contraception 1995;51:221-4.

27 Hartard M, Bottermann P, Bartenstein P, et al. Effects on bone mineral density of low-dosed oral contraceptives compared to and combined with physical activity. Contraception 1997;55:87-90.

28 Register TC, Jayo MJ, Jerome CP. Oral contraceptive treatment inhibits the normal acquisition of bone mineral in ment inhibits the normal acquisition of bone mineral in oporos Int 1997; 7:348-53.

29 Prior JC, Kreiger JN, Tenenhouse A, et al. No positive effect of oral contraceptive use on bone density: a populationbased cross-sectional study in women aged $25-45$ from the Canadian Multicentre Osteoporosis study. Bone 1998; 23(suppl):S304

30 Cooper C, Hannaford P, Croft P, et al. Oral contraceptive pill use and fractures in women: a prospective study. Bone 1993;14:41-5.

31 Drinkwater BL, Nilson $\mathrm{K}$, Chesnut $111 \mathrm{CH}$, et al. Bone mineral content of amenorrheic and eumenorrheic athletes. $N$ Engl F Med 1984;5:277-81.

32 Micklesfield LK, Lambert EV, Fataar AB, et al. Bone mineral density in mature, premenopausal ultramarathon runners. Med Sci Sports Exerc 1995;27:688-96.

33 Robinson TL, Snow-Harter C, Taaffe DR, et al. Gymnasts exhibit higher bone mass than runners despite similar exhibit higher bone mass than runners despite similar prevalence of amenorrhe

34 Tomten SE, Falch JA, Birkeland KI, et al. Bone mineral density and menstrual irregularities: a comparative study on cortical and trabecular bone structures in runners with alleged normal eating behaviour. Int $\mathcal{F}$ Sports Med 1998;19: 92-7.

35 Pettersson U, Stalnacke BM, Ahlenius GM, et al. Low bone mass density at multiple skeletal sites, including the appendicular skeleton in amenorrheic runners. Calcif Tissue Int 1999;64:117-25.

36 Prior JC, Vigna YM, Schechter MT, et al. Spinal bone loss and ovulatory disturbances. N Engl f Med 1990;323:12217 .

37 Prior JC, Vigna YM, Barr SI, et al. Ovulatory premenopausal women lose cancellous spinal bone; a five year prospecsal women lose cancellous spinal
tive study. Bone 1996;18:261-7.

38 Stacey E, Korkia P, Hukkanen MVJ, et al. Decreased nitric oxide levels and bone turnover in amenorrheic athletes with spinal osteopenia. F Clin Endocrinol Metabol 1998;83:3056-

39 Zanker CL, Swaine IL. Relation between bone turnover, oestradiol, and energy balance in women distance runners. Br F Sports Med 1998;32:167-71.

40 Zanker CL, Swaine IL. Bone turnover in amenorrheic and eumenorrheic women distance runners. Scand $\mathcal{F} \mathrm{Med} S \mathrm{Sc}$ Sport 1999;8:20-6.

41 Cann CE, Cavanaugh DJ, Schnurpfiel K, et al. Menstrual history is the primary determinant of trabecular bone density in women runners. Med Sci Sports Exerc 1988;20:59.

42 Hergenroeder AC, Smith EOB, Shypailo R, et al. Bone mineral changes in young women with hypothalamic amenorrhea treated with oral contraceptives, medroyxprogesterone, or placebo over 12 months. Am f Obstet Gynecol 1997; 176:1017-25.
43 De Cree C, Lewin R, Ostyn M. Suitability of cyproterone acetate in the treatment of osteoporosis associated with athletic amenorrhea. Int $\mathcal{F}$ Sports Med 1988;9:187-92.

44 Cumming D. Exercise-associated amenorrhea, low bone density, and estrogen replacement therapy. Arch Intern Med 1996;156:2193-5.

45 Prior JC, Vigna YM, Barr SI, et al. Cyclic medroxyprogesterone treatment increases bone density: a controlled trial in active women with menstrual cycle disturbances. $A m$ f Med 1994;96:521-30.

46 Withdrawn

47 Carter DR, Hayes WC, Schurman DJ. Fatigue life of compact bone. II. Effects of microstructure and density. F Biomech 1976;9:211-18.

48 Heaney RP, Recker RR, Saville PD. Menopausal changes in calcium balance performance. $\mathcal{F}$ Lab Clin Med 1978;92: 953-63.

49 Slemenda C, Hui SL, Longcope C, et al. Sex steroids and bone mass. A study of changes about the time of menopause. 7 Clin Invest 1987;80:1261-9.

50 Hansen MA, Overgaard K, Christiansen C. Spontaneous postmenopausal bone loss in different skeletal areas:
followed up for 15 years. F Bone Miner Res 1995;10:205-10.

51 Carbon R, Sambrook PN, Deakin V, et al. Bone density of elite female athletes with stress fractures. Med f Austr 1990;153:373-6.

52 Frusztajer NT, Dhuper S, Warren MP, et al. Nutrition and the incidence of stress fractures in ballet dancers. Am f Clin Nutr 1990;51:779-83.

53 Myburgh KH, Hutchins J, Fataar AB, et al. Low bone density is an etiologic factor for stress fractures in athletes. Ann Intern Med 1990;113:754-9.

54 Grimston SK, Engsberg JR, Kloiber R, et al. Bone mass, external loads, and stress fractures in female runners. International fournal of Sport Biomechanics 1991;7:293-302.

55 Bennell KL, Malcolm SA, Thomas SA, et al. Risk factors for stress fractures in female track-and-field athletes: a retrospective analysis. Clin f Sport Med 1995;5:229-35.

56 Cline AD, Jansen GR, Melby CL. Stress fractures in female army recruits: implications of bone density, calcium intake, and exercise. $\mathcal{F}$ Am Coll Nutr1998;1 1:128-35.

57 Bennell KL, Malcolm SA, Thomas SA, et al. Risk factors for stress fractures in track and field athletes: a 12 month prospective study. Am f Sports Med 1996;24:810-18.

58 Lloyd T, Triantafyllou SJ, Baker ER, et al. Women athletes with menstrual irregularity have increased musculoskeletal injuries. Med Sci Sports Exerc 1986;18:374-9.

59 Warren MP, Brooks-Gunn J, Hamilton LH, et al. Scoliosis and fractures in young ballet dancers. N Engl f Med 1986; 314:1348-53.

60 Barrow GW, Saha S. Menstrual irregularity and stress fractures in collegiate female distance runners. Am $\mathcal{F}$ Sports Med 1988;16:209-16.

61 Kadel NJ, Teitz CC, Kronmal RA. Stress fractures in ballet dancers. Am F Sports Med 1992;20:445-9.

62 Winfield AC, Bracker M, Moore J, et al. Risk factors associated with stress reactions in female marines. Mil Med 1997; 162:698-702.

63 Clark N, Nelson M, Evans W. Nutrition education for elite female runners. Physician and Sports Medicine 1988;16: 124-36.

64 Erdelyi G. Gynaecological survey of female athletes. 7 Sports Med 1962;2:174-9.

65 Wojtys EM, Huston LJ, Lindenfeld TN, et al. Association between the menstrual cycle and anterior cruciate ligament injuries in female athletes. Am $\mathcal{F}$ Sports Med 1998;26:61419 .

66 Moller-Nielson J, Hammer M. Women's soccer injuries in relation to the menstrual cycle and oral contraceptives. Med Sci Sports Exerc 1989;21:126-9.

67 Bennell KL, Crossley K. Musculoskeletal injuries in track and field: incidence, distribution and risk factors. Aust $\mathcal{F}$ Sci Med Sport 1996;28:69-75.

68 Thompson HS, Hyatt JP, Desouza MJ, et al. The effects of oral contraceptives on delayed onset muscle soreness following exercise. Contraception 1997;56:59-65.

69 Brynhildsen JO, Hammer J, Hammer ML Does the menstrual cycle and use of oral contraceptives influence the risk of low back pain? A prospective study among female soccer players. Scand F Med Sci Sports 1997;7:348-53.

70 Daugherty JE. Treatment strategies for premenstrual syndrome. Am Fam Physician 1998;58:183-92.

71 Rougier G, Linquette Y. Menstruation and physical exercise. Presse Medicale 1962;70:1921-3.

72 Posthuma BW, Bass MJ, Bull SB, et al. Detecting changes in functional ability in women with premenstrual symptoms. Am $\mathcal{7}$ Obstet Gynecol 1987;156:275-8.

73 Hama H, Yamamuro T, Takeda T. Experimental studies on connective tissue of the capsular ligament. Influence of aging and sex hormones. Acta Orthop Scand 1976;47:4739.

74 Smith BA, Livesay GA, Woo SL. Biology and biomechanics of the anterior cruciate ligament. Clin Sports Med 1993;12: 637-70.

75 Liu SH, Al-Shaikh RA, Panossian V, et al. Estrogen affects the cellular metabolism of the anterior cruciate ligament. Am F Sports Med 1997;25:704-9.

76 Sciore P, Frank CB, Hart DA. Identification of sex hormone receptors in human and rabbit ligaments of the knee by reverse transcription-polymerase chain reaction: evidence that receptors are present in tissue from both male and female subject. F Orthop Res 1998;16:604-10. 
77 Daggett A, Davies B, Boobis L. Physiological and biomechanical responses to exercise following oral contraceptive use. Med Sci Sports Exerc 1983;15:174

78 Lebrun CM. Effect of the different phases of the menstrual cycle and oral contraceptives on athletic performance. Sports Med 1993;16:400-30.

79 Notelovitz M, Zauner C, McKenzie L, et al. The effect of low-dose contraceptives on cardiorespiratory function, coagulation, and lipids in exercising young women: preliminary report. Am F Obstet Gynecol 1987;156:591-8.

79a Bryner W, Toffle RC, Ullrich IH, et al. Effect of low dose oral contraceptives on exercise performance, $\mathrm{Br} \mathcal{F}$ Sports Med 1996;30:36-40.

80 De Bruyn-Prevost P, Masset C, Sturbois X. Physiological response from 18-25 year old women to aerobic and anperobic physical fitness tests at different periods during the menstrual cycle. 7 Sports Med 1984;24:144-8.

81 Lynch NJ, Nimmo MA. Effects of menstrual cycle phase and oral contraceptive use on intermittent exercise. Eur $\mathcal{f}$ Appl Physiol 1998;78:565-72.

82 Fogelholm $M$. Indicators of vitamin and mineral status in athletes blood: a review. Int $\mathcal{f}$ Sport Nutr 1995;5:267-84.

83 Nuviala RJ, Castillo MC, Lapieza MG, et al. Iron nutritional status in female karatekas, handball and basketball players and runners. Physiol Behav1996;59:449-53.

84 Littler WA, Bojorges-Bueno R, Banks J. Cardiovascular dynamics in women during the menstrual cycle and ora contraceptive therapy. Thorax 1974;29:567-70.

85 Lehtovirta P, Kuikka J, Pyorala T. Hemodynamic effects of oral contraceptives during exercise. Int f Gynaecol Obstet 1977;15:35-7.
86 Phillips SK, Rook KM, Siddle NC, et al. Muscle weakness in women occurs at an earlier age than men but strength is preserved by hormone replacement therapy. Clin Sci 1993; 84:95-8.

87 Petrofsky JS, Ledonne DM, Rinehart JS, et al. Isometric strength and endurance during the menstrual cycle. Eur $\mathcal{F}$ Appl Physiol 1976;35:1-10.

88 Phillips SK, Sanderson AG, Birch K, et al. Changes in maximal voluntary force of human adductor pollicis muscle during the menstrual cycle. F Physiol 1996;496:551-7.

89 Sarwar R, Niclos BB, Rutherford OM. Changes in muscle strength, relaxation rate and fatiguability during the human menstrual cycle. F Physiol (Lond) 1996;493:267-72.

90 Wirth JC, Lohman TG. The relationship of static muscle function to use of oral contraceptives. Med Sci Sports Exerc 1982;14:16-20.

91 Gray DP, Harding E, Dale E. Effects of oral contraceptives on serum lipid profiles of women runners. Fertil Steril 1983;39:510-14.

92 Gossain VV, Sherma NK, Michelakis AM, et al. Effect of oral contraceptives on plasma glucose levels, insulin and oral contraceptives on plasma glucose levels, insulin

93 Skouby SO, Andersen O, Petersen KR, et al. Mechanism of action of oral contaceptives on carbohydrate metabolism at the cellular level. Am f Obstet Gynecol 1990;163:343-8.

94 Bemden DA, Boileau RA, Bahr JM, et al. Effects of oral contraceptives on hormonal and metabolic responses during exercise. Med Sci Sports Exerc 1992;24:434-41.

95 Bonen A, Haynes FW, Graham TE. Substrate and hormonal responses to exercise in women using oral contraceptives. F Appl Physiol 1991;70:1817-27.

\section{Palliative care and sports medicine: can the decision making process ever overlap?}

The voluntary medical standards of the UK Sport Diving Medical Committee are supported by a small network of medical referees for specialist opinion, of which I am one. In October 1996, a 37 year old woman presented for a sport diving medical. She had metastatic malignant melanoma treated six months previously by pneumonectomy and chemotherapy. She was already an experienced diver and wished to go on a Red Sea holiday with her partner, before trying diving in Scotland again. Her partner accompanied her at the medical and was intelligent, articulate, and had a good understanding of the risks involved.

She was on no medication and her remaining lung showed normal function. The obvious theoretical risk in such circumstances is pulmonary barotrauma and arterial gas embolism. A stiff tethered lung might easily collapse and cause a fatal tension pneumothorax (she proved her exercise tolerance in the swimming pool). She felt physically cured and she wanted to be mentally cured by achieving her sporting goal.

However, medical reality suggests that metastatic malignant melanoma is never physically curable. What are the risks of sporting diving and can they be quantified precisely? In diving medicine, like many branches of medicine, there are few certainties, many grey areas, and not enough numbers to support decisions.

Faced with such circumstances, a doctor returns to first principles. Hippocrates said "First do no harm". I had no certain evidence to say it definitely would cause harm and indeed denying the opportunity of rehabilitation may prove harmful. Secondly, apply palliative care principles that revolve around quality of life rather than quantity of life. Thirdly, apply the principle of informed consent to the potential sportswoman and for her partner. He also had to understand the risks as the dive buddy and potential rescuer in a crisis.

I passed her fit and she returned 12 months later to recount her stories of the Red Sea and the West Coast of Scotland. She thanked me further for taking the medical risk and helped another patient with metastatic melanoma. She was full of life but only lived six months, when she sadly died from cerebral metastases.

Sport diving does not have the sporting heroes of competition sports. This sporting patient inspired many people in her short life and remains my personal sporting hero.

J D M DOUGLAS Fort William 